\title{
Knowledge, Awareness and Self-Care Practices of Hypertension among Cardiac Hypertensive Patients
}

\author{
Muhammad Bilal $^{1}$, Abdul Haseeb ${ }^{1}$, Sehan Siraj Lashkerwala ${ }^{1}$, Ibrahim Zahid ${ }^{1}$, Khadijah Siddiq ${ }^{1}$, Muhammad \\ Saad $^{2}$, Mudassir Iqbal Dar ${ }^{3}$, Mohammad Hussham Arshad ${ }^{4}$, Waqas Shahnawaz ${ }^{5}$, Bilal Ahmed ${ }^{5}$ \& Aimen Yaqub \\ ${ }^{1}$ Dow University of Health Sciences, Karachi, Pakistan \\ ${ }^{2}$ Department of Pulmonology, Jinnah Postgraduate Medical Center, Karachi, Pakistan \\ ${ }^{3}$ Cardiac Surgery Department, Civil Hospital, Karachi, Pakistan \\ ${ }^{4}$ Aga Khan University Hospital, Karachi, Pakistan \\ ${ }^{5}$ The Lyceum, Karachi, Pakistan \\ Correspondence: Muhammad Bilal, Dow University of Health Sciences, Karachi, Pakistan, A/215, Block: 5, \\ Gulshan-e-Iqbal, Karachi, Pakistan. Tel: 92-324-222-0872. E-mail: bilalmemon_744@hotmail.com
}

Received: March 24, 2015

doi:10.5539/gjhs.v8n2p9
Accepted: April 24, $2015 \quad$ Online Published: June 1, 2015

URL: http://dx.doi.org/10.5539/gjhs.v8n2p9

\begin{abstract}
Introduction: The most prevalent form of hypertension is systolic blood pressure (SBP) and it is considered to be predisposing risk factor for cardiovascular disease. The objective of the study was to assess self-care practices, knowledge and awareness of hypertension, especially related to SBP among cardiac hypertensive patients.

Methodology: A Cross sectional study was conducted on 664 cardiac hypertensive patients, which were selected by non-probability convenience sampling from cardiology outpatient department of three tertiary care hospitals. Face to face interviews were conducted using a pre designed questionnaire. Data was entered and analyzed by SPSS (V17).

Results: $81.8 \%$, did not know that hypertension is defined as high blood pressure. $97.1 \%$ of the sample population did not know that top measurement of blood pressure was referred to as systolic and only $25.0 \%$ correctly recognized normal systolic blood pressure to be less than $140 \mathrm{mmHg}$. $7.4 \%$ of the patients consulted their doctor for hypertension once or twice in a month. Risk factor for high blood pressure most commonly identified by the participants was too much salt intake

Conclusions: The results state that there is an inadequate general knowledge of hypertension among cardiac patients and they do not recognise the significance of elevated SBP levels. There is a need to initiate programs that create community awareness regarding long term complications of uncontrolled hypertension, particularly elevated SBP levels so that there is an improvement in self-care practices of the cardiacpatients.
\end{abstract}

Keywords: systolic blood pressure, hypertension, cardiac patients, outpatient department, tertiary care hospitals

\section{Introduction:}

Considered as the silent killer (Hoel \& Howard, 1997), high arterial Blood Pressure (BP) is the greatest causative agent for the mortality involved in cardiovascular diseases, renal failure and stroke (Rahimi\&Rahimi, 2006). The studies conducted on global burden of Hypertension (HTN) reported that $25 \%$ of adults are having HTN and $9.2 \%$ of the total deaths are because of high BP related events (Lawes, Vander Hoom, \& Rodgers, 2008). As indicated by the epidemiological data, hypertension accounts for $35 \%$ of all atherosclerotic events and $49 \%$ of all cases of heart failure. It increases two to three folds of an individual's risk for cardiovascular disease (Padwal, Strauss, \& McAlister, 2001). Worldwide analysis show that the number of people with uncontrolled hypertension (>140/90 mm of $\mathrm{Hg}$ ) rose from 600 million in 1980 to nearly 1 billion in 2008 and this number is expected to increase to 1.56 billion by 2025 , which will approximately be $29 \%$ of the worldwide adult population (Sarafidis et al., 2008).

In Pakistan one in every three individual over the age of 45 years is hypertensive as revealed by the National Health Survey (NHS) (Nishtar, Faruqui, Mattu, Mohamud, \& Ahmed, 2004). According to the "Sixth Report of the Joint National Committee on Prevention, Detection, Evaluation, and Treatment of High Blood Pressure", 
Blood pressure is classified on the basis of Systolic blood pressure (SBP) and Diastolic blood pressure (DBP) (Lloyd-Jones, Evans, Larson, O'Donnell, \& Levy, 1999). The most prevalent form of HTN is SBP and people aged above 60 years are more prone to it. Studies have shown that it is more important to control systolic blood pressure (SBP) than diastolic blood pressure (DBP) (Levine et al., 2003). Also, SBP alone is a predisposing risk factor for cardiovascular disease (CVD).Treatment and control of BP reduces the risk for cardiovascular diseases (Verdecchia, Angeli, Gentile, Mazzotta, \& Reboldi, 2011). The 1990 to 1994 National Health Survey of Pakistan also showed that about $70 \%$ to $85 \%$ of Pakistani hypertensive patients were unaware of their disease, indicating limited awareness of hypertension (National Health Survey of Pakistan 1990-1994).Since there is no information available if the patients know the importance of their SBP level (Izzo, Levy, \& Black, 2000), an opportunity exists to find the knowledge and awareness of the patients in controlling their SBP level.

Local data in relation to cardiac hypertensive patients is scarce, which made it necessary to conduct this study in this area to determine the association of knowledge of SBP and CVD in cardiac hypertensive population. This can help us modify the treatment options, reduce adverse outcomes and provide better health care services. The objective of the study was to assess self-care practices, knowledge and awareness of hypertension, especially related to SBP among cardiac hypertensive patients attending cardiology outpatient department (OPD) of tertiary care hospitals.

\section{Methodology}

A descriptive, cross-sectional study was conducted to evaluate the knowledge, awareness and self-care practices of hypertension among cardiac hypertensive patients. Six-sixty four patients were interviewed from the cardiology outpatient department to obtain the required information. The sample size of 664 was determined assuming percentage knowledge of HTN among cardiac patients to be 50\% (taking 99\% level of significance and $1 \%$ confidence limit). The blood pressure of patients was inquired by directly asking them. The study was performed after the approval from the Institutional Review Board of the Dow University of Health Sciences.

A multi-center study was conducted at the cardiology OPD of National Institute of Cardio-Vascular Diseases (NICVD), Abbasi Shaheed Hospital and Civil Hospital, Karachi. The NICVD being the largest cardiovascular tertiary care hospital of Karachi, receives patients from all over Karachi, and even from the remote areas of Sindh; while the other two, located at the two ends of the district, make it possible to cover patients from different areas of Karachi. The patients from the OPD were selected by non-probability convenience sampling, over a period of one week to prevent repetition of participants in the sample. Patients aged below 18 and pregnant women were excluded from the population, and so were the patients presenting with complications of hypertension like stroke, cerebrovascular accidents etc. and patients presenting with co morbidities like diabetes mellitus and renal failure. While the inclusion criteria included patients who were 18 and above, suffering from known pathology of valvular, ischemic heart disease or both. A patient was considered as hypertensive if he has $\mathrm{BP}>140 / 90 \mathrm{~mm}$ of $\mathrm{Hg}$ or a lower BP on anti-hypertensive drugs. An interview based questionnaire was presented to each of the participant by the researcher in the homogeneous manner to limit interview biases. The first part of the questionnaire comprised of patients demographics followed by the clinical history of the patient; the second part dealt with the knowledge and awareness of hypertension with special relation to SBP, and the last part was regarding the self-care practices and management of hypertension.

The collected data was entered on SPSS (V17) software. The same software was used for data management and analysis. Mean and standard deviation were calculated for all quantitative variables like age, SBP and DBP etc. Frequency and percentages were calculated for all qualitative variables like gender etc. Chi-square test was used to find out the association benefits of study between outcome variable (knowledge of HTN) and other factors like gender, education and socio-economic status.

\section{Results}

A total of 664 cardiac hypertensive patients were included in the study consisting of 422 males and 242 females, giving a male to female ratio of 1.7:1. Table 1 depicts the demographic characteristics of cardiac hypertensive patients. Out of these 664 patients, 582 were married. The mean age of the patients was $54.4 \pm 12.5$ years. Three hundred and sixty three (54.7\%) of the participants were either illiterate or with level of education less than Matriculation (equivalent to grade 10$)$. One hundred and thirty three $(20.0 \%)$ of the participants were labor by profession. Consequently, monthly household income of $152(22.9 \%)$ participants was between Rs.5000 and Rs.20000.

Table 2 shows the clinical history of cardiac hypertensive patients. Patients undergone angioplasty or coronary artery bypass graft surgery $(\mathrm{CABG})$ were $16.3 \%(\mathrm{~N}=108)$ of the sample population and $42.8 \%(\mathrm{~N}=284)$ have been admitted in the hospital at least once in their lifetime due to uncontrolled blood pressure. Majority of the 
participants, 597(89.9\%), were using medications for hypertension. Most of the cardiac hypertensive patients, $169(25.5 \%)$, said that they were hypertensive from a time period of 6 months- 2 years. Out of 664 participants, $347(52.3 \%)$ were aware of their blood pressure reading on their last visit which had a mean systolic blood pressure (SBP) of $144.6 \mathrm{~mm} \mathrm{Hg}(\mathrm{SD}=33.2 \mathrm{~mm} \mathrm{Hg}$ ) and mean diastolic blood pressure (DBP) of $94.0 \mathrm{~mm} \mathrm{Hg}$ $(\mathrm{SD}=23.7 \mathrm{~mm} \mathrm{Hg})$. No family history of any disease was found in $48.5 \%(\mathrm{~N}=322)$ of the participants, however majority of the remaining participants had a family history of cardiovascular disease, $(\mathrm{n}=214,32.2 \%)$.

Furthermore, $85.8 \%(\mathrm{~N}=570)$ of the patients claimed hypertension to be very dangerous and $89.6 \%(\mathrm{~N}=595)$ agreed that controlling blood pressure can improve a person's health. Five hundred and forty three $(81.8 \%)$ did not know that hypertension is defined as high blood pressure. Five hundred and twenty (78.3\%) believed that it's very important to take medicines to keep blood pressure under control. Majority of the sample population, $97.1 \%$ $(\mathrm{N}=645)$, did not know that top measurement of blood pressure was referred to as systolic and $96.8 \%(\mathrm{~N}=643)$ did not know that bottom measurement of blood pressure was referred to as diastolic. Participants who either did not know or identified normal systolic blood pressure (SBP) to be equal to $140 \mathrm{~mm} \mathrm{Hg}$ or greater than $140 \mathrm{~mm}$ $\mathrm{Hg}$ were $50.2 \%$ of the sample population. In case of normal diastolic blood pressure (DBP), $52.6 \%$ of the participants did not know or identified the value to be equal to $90 \mathrm{~mm} \mathrm{Hg}$ or greater than $90 \mathrm{~mm} \mathrm{Hg}$. When asked, which measure do you think is important, $70.9 \%$ were unaware. A similar outcome was seen when asked about the number responsible in causing cardiovascular disease, and $83 \%(\mathrm{~N}=551)$ of them did not know. Two hundred and thirty seven patients (35.7\%) claimed to have high blood pressure at their last checkup. Results of questions relating to hypertension knowledge in cardiac hypertensive patients are given in table 3.

Table 4 gives the data regarding the awareness of cardiac hypertensive patients in relation to hypertension risk factors and complications. Risk factor most commonly identified by the participants was too much salt intake $(\mathrm{N}=523,78.8 \%)$. Heart attack and stroke as a complication was recognized by $374(56.3 \%)$ and $185(27.9 \%)$ participants, respectively.

Table 5 show answers to the questions related to the self-care practices of hypertension carried out by the sample population. When asked, do you regularly check your blood pressure, $459(69.1 \%)$ claimed to check it regularly with most of them checking monthly, $234(35.2 \%)$. Three hundred and forty three $(51.7 \%)$ patients get their blood pressure checked at the nearest health care facility. Five hundred and forty six $(82.2 \%)$ do not have a sphygmomanometer at home and $220(33.1 \%)$ of them reasoned that they did not feel the need to have it. Most of the patients, $265(39.9 \%)$, consulted doctor of hypertension every 3-6 months and $180(27.1 \%)$ consulted their cardiologist more than every 12 months. Majority of the participants, $213(32.1 \%)$ get their ECG examined more than every 6 months and $239(36 \%)$ get their cholesterol checked more often than every 6 months. Taking medication was the single most important practice carried out by most of the cardiac hypertensive patients $(\mathrm{n}=329,49.5 \%)$.

Further analyses were performed using demographic characteristics in which these outcomes were statistically analyzed. In general, there were no specific differences in knowledge, awareness, or self-care practices among the subgroups. Patients who had a master's degree showed better understanding of hypertension than comparatively less educated patients. These patients specifically showed a better knowledge of the definition of hypertension (e.g., $31.6 \%$ of the participants with masters education knew that hypertension is high blood pressure compared to participants with less than master's degree; $\mathrm{P}<0.001)$. In addition, businessmen tend to report better knowledge of hypertension compared to patients with other professions (e.g. $26.3 \%$ of the businessmen knew that hypertension means high blood pressure compared to patients with other professions; $\mathrm{P}<0.001)$.Participants with a better socioeconomic status were seen to carry out more self-care practices compared to people with low monthly household income (e.g. $76.2 \%$ of participants with monthly household income > Rs.20000 regularly checked their blood pressure compared to participants with monthly household income $<$ Rs.20000; $\mathrm{P}<0.001)$. 
Table 1. Demographic characteristics of cardiac hypertensive patients $(\mathrm{N}=664)$

\begin{tabular}{|c|c|c|}
\hline Demographic characteristics & $\mathbf{N}$ & $\%$ \\
\hline Age (years) Mean \pm SD & $54.4 \pm 12.5$ & - \\
\hline \multicolumn{3}{|l|}{ Gender } \\
\hline Male & 422 & 63.6 \\
\hline Female & 242 & 36.4 \\
\hline \multicolumn{3}{|l|}{ Marital Status } \\
\hline Single & 31 & 4.7 \\
\hline Married & 582 & 87.7 \\
\hline Divorced & 1 & 0.2 \\
\hline Widowed & 50 & 7.5 \\
\hline \multicolumn{3}{|l|}{ Level of education } \\
\hline Matriculation (grade 10) & 157 & 23.6 \\
\hline Intermediate (grade 12) & 71 & 10.7 \\
\hline Bachelors & 54 & 8.1 \\
\hline Masters & 19 & 2.9 \\
\hline No education & 363 & 54.7 \\
\hline \multicolumn{3}{|l|}{ Profession } \\
\hline Labor & 133 & 20.0 \\
\hline Businessman & 19 & 2.9 \\
\hline Government employee & 39 & 5.9 \\
\hline Private employee & 101 & 15.2 \\
\hline Housewife & 186 & 28.0 \\
\hline Retired & 186 & 28.0 \\
\hline \multicolumn{3}{|l|}{ Monthly household income } \\
\hline Less than 5000 & 49 & 7.4 \\
\hline $5000-20000$ & 152 & 22.9 \\
\hline 20001-50000 & 94 & 14.2 \\
\hline $50001-100000$ & 6 & 0.9 \\
\hline Greater than 100000 & 5 & 0.8 \\
\hline Not applicable & 358 & 53.9 \\
\hline
\end{tabular}

Table 2. Clinical history of cardiac hypertensive patients $(\mathrm{N}=664)$

\begin{tabular}{lcc}
\hline Clinical history & N & \% \\
\hline Are you currently on HTN medication? & & \\
Yes & 597 & 89.9 \\
No & 67 & 10.1 \\
For how long have you been suffering from HTN? & \\
< 6 Months & 149 & 22.4 \\
6 Months - 2 Years & 169 & 25.5 \\
2.1 - 5 Years & 149 & 22.4 \\
\hline
\end{tabular}




\begin{tabular}{lcc}
\hline $\mathbf{5 . 1}$ - 15 Years & 130 & 19.6 \\
$>\mathbf{1 5}$ Years & 67 & 10.0 \\
History of angioplasty/CABG & & \\
Yes & 108 & 16.3 \\
No & 556 & 83.7
\end{tabular}

Have you ever been admitted to the hospital because of uncontrolled BP?

Yes

$284 \quad 42.8$

No

$380 \quad 57.2$

Family history of any disease

Cardiovascular disease

$214 \quad 32.2$

Diabetes

$100 \quad 15.1$

Hyperlipidemia/Dyslipidemia

$8 \quad 1.2$

Cerebrovascular disease

$7 \quad 1.1$

Renal disease

13

2.0

None

322

48.5

Are you aware of your BP reading from your last visit?

$\begin{array}{lll}\text { Yes } & 347 & 52.3 \\ \text { No } & 317 & 47.7 \\ \text { SBP/mm of Hg } & 144.6 \pm 33.2 & \\ \text { DBP/mm of } \mathbf{~ g g} & 94.0 \pm 23.7 & \end{array}$

Table 3. Hypertension knowledge $(\mathrm{N}=664)$

\begin{tabular}{lcc}
\hline Hypertension Knowledge & N & \% \\
What is the definition of HTN? & & \\
High BP & 53 & 8.0 \\
High level of stress/tension & 29 & 4.4 \\
Nervous condition & 19 & 2.9 \\
High Blood Sugar & 4 & 0.6 \\
Over activity & 16 & 2.4 \\
Don't Know & 543 & 81.8 \\
How dangerous is HTN to your health? & & \\
Very dangerous & 570 & 85.8 \\
Not dangerous at all & 94 & 14.2 \\
Can lowering high BP improve a person's health? & & \\
Yes & 595 & 89.6 \\
No & 69 & 10.4 \\
What does the top number of blood pressure represent? & \\
Systolic & 19 & 2.9 \\
Diastolic & 3 & 0.5 \\
Both & 2 & 0.3 \\
Don't know & 640 & 96.4 \\
\hline
\end{tabular}


What does the bottom number of blood pressure represent?

Systolic

Diastolic

Both

Don't know

What should be the normal top number?

$<140$

140

$>140$

Don't know

What should be the normal bottom number?

$<90$

90

$>90$

Don't know

Which measure do you think is important?

Top

Bottom

$54 \quad 8.1$

Both

$338 \quad 50.9$

Don't know

Which number is responsible in causing Cardiovascular disease?

Top

$59 \quad 8.9$

Bottom

$26 \quad 3.9$

Both

$28 \quad 4.2$

Don't know

$551 \quad 83.0$

What do you think your BP was at the last visit?

$\begin{array}{lll}\text { High } & 237 & 35.7 \\ \text { Normal } & 200 & 30.1 \\ \text { Low } & 11 & 1.7 \\ \text { Don't know } & 216 & 32.5\end{array}$

How important do you think medicine is to keep BP under control?

Very important

$520 \quad 78.3$

Not important at all

$25 \quad 3.8$

Don't know

$119 \quad 17.9$

Is high BP(HTN) a lifelong disease?

Yes

$420 \quad 63.3$

No

$244 \quad 36.7$

Do you think high BP(HTN) is something that you can cure?

Yes

$605 \quad 91.1$

No

$59 \quad 8.9$ 
Table 4. Awareness about risk factors and complications of hypertension

\begin{tabular}{lll}
\hline Are you aware of the following risk factors of HTN? & N & \% \\
\hline Too much salt intake is a risk factor of HTN & 523 & 78.8 \\
Tension is a risk factor of HTN & 354 & 53.3 \\
Lack of exercise is a risk factor of HTN & 90 & 13.6 \\
Inheritance is a risk factor of HTN & 64 & 9.6 \\
High cholesterol is a risk factor of HTN & 314 & 47.3 \\
Obesity is a risk factor of HTN & 168 & 25.3 \\
Smoking is risk factor of HTN & 155 & 23.3 \\
Aging is a risk factor of HTN & 104 & 15.7 \\
Diabetes is a risk factor of HTN & 123 & 18.5 \\
Alcohol abuse is a risk factor of HTN & 62 & 9.3 \\
Which of the following complications of HTN are you aware of? & & \\
Heart attack is a complication of HTN & 374 & 56.3 \\
Stroke is a complication of HTN & 185 & 27.9 \\
Aneurysm is a complication of HTN & 20 & 3.0 \\
Narrowed blood vessels in kidney is a complication of HTN & 66 & 9.9 \\
Narrowed blood vessels in eye is a complication of HTN & 98 & 14.8 \\
Metabolic syndrome is a complication of HTN & 21 & 3.2 \\
Trouble with memory or understanding is complication of HTN & 107 & 16.1 \\
\hline
\end{tabular}

Table 5. Self-care practices of cardiac hypertensive patients $(\mathrm{N}=664)$

\begin{tabular}{lll}
\hline Self-care practices & N & $\mathbf{\%}$ \\
\hline Do you have a home sphygmomanometer? & 118 & 17.8 \\
Yes & 546 & 82.2 \\
No & & \\
Do you regularly check your BP? & 459 & 69.1 \\
Yes & 205 & 30.9 \\
No & & \\
If yes, how often do you check your BP? & 66 & 9.9 \\
Daily & 119 & 17.9 \\
Weekly & 234 & 35.2 \\
Monthly & 36 & 5.4 \\
Every 3 months & 4 & .6 \\
More than that & & \\
If yes, from where do you get your BP checked? & 83 & 12.5 \\
At home & 33 & 5.0 \\
At tertiary hospital & 343 & 51.7 \\
Nearest health care facility & & \\
What are the barriers towards self-testing for BP? & 168 & 25.3 \\
Expensive & 152 & 22.9 \\
\hline Lack of awareness & & \\
\hline
\end{tabular}




\begin{tabular}{|c|c|c|}
\hline Pain & 6 & 0.9 \\
\hline Don't feel the need & 220 & 33.1 \\
\hline None & 118 & 17.7 \\
\hline \multicolumn{3}{|c|}{ How often do you consult your doctor for HTN? } \\
\hline Once/twice in a month & 49 & 7.4 \\
\hline Every 2 months & 54 & 8.1 \\
\hline Every 3-6 months & 139 & 20.9 \\
\hline Every 6-12 months & 265 & 39.9 \\
\hline More than 12 months & 157 & 23.6 \\
\hline \multicolumn{3}{|c|}{ How often do you consult your cardiologist for heart exam? } \\
\hline Once/twice in a month & 50 & 7.5 \\
\hline Every 2 months & 70 & 10.5 \\
\hline Every 3-6 months & 130 & 19.6 \\
\hline Every 6-12 months & 180 & 27.1 \\
\hline More than 12 months & 234 & 35.2 \\
\hline \multicolumn{3}{|l|}{ How often do you get your ECG examined? } \\
\hline \multicolumn{3}{|l|}{ Once/twice in a lifetime } \\
\hline Monthly & 189 & 28.5 \\
\hline Every 3 months & 25 & 3.8 \\
\hline Every 6 months & 118 & 17.8 \\
\hline More than that & 213 & 32.1 \\
\hline Never & 119 & 17.9 \\
\hline \multicolumn{3}{|c|}{ How often do you get your blood cholesterol checked? } \\
\hline Once/twice in a lifetime & 148 & 22.3 \\
\hline Monthly & 122 & 18.4 \\
\hline Every 3 months & 11 & 1.7 \\
\hline every 6 months & 54 & 8.1 \\
\hline More than that & 239 & 36.0 \\
\hline Never & 90 & 13.6 \\
\hline \multicolumn{3}{|c|}{ Which single most important practice do you carry out to control your high BP? } \\
\hline \multicolumn{3}{|l|}{ Taking medication } \\
\hline Rhythmic exercise & 329 & 49.5 \\
\hline Less stress & 67 & 10.1 \\
\hline Quitting smoking & 46 & 6.9 \\
\hline Reducing salt content in diet & 48 & 7.2 \\
\hline DASH diet ( diet approaches to stop HTN) & 149 & 22.4 \\
\hline Losing weight & 25 & 3.8 \\
\hline
\end{tabular}

\section{Discussion}

A descriptive study was conducted to assess the up-to-date information on knowledge, awareness and self-care practices of HTN among cardiac hypertensive patients in Karachi. We found that the awareness level of cardiac hypertensive patients in general is inadequate. The patients are not informed about recently recommended guidelines, cutoff values of SBP and association of their SBP levels with cardiovascular disease. Consequently, 
$48 \%$ of the patients could not recall their BP value and were unable to report whether their BP value is elevated or normal. Our results also revealed insufficient self-care practices of cardiac patients towards their BP control. However, prompt management leads to lower incidence of complications (Staessen, Wang, \& Thijs, 2001) and reducing the complications of HTN is an issue of great attention (Kearney, Whelton, Reynolds, Whelton, \& He, 2004).

Alarmingly, very limited numbers of cardiac patients $(8 \%)$ were aware about the correct definition of HTN and majority of the patients (82\%) did not know anything about this term. Less than $3 \%$ could identify the top and bottom number of BP reading as systolic and diastolic correctly. This reveals poor awareness level of the participants. This is fairly consistent with the findings of another Pakistani study which has also narrated inadequate awareness among hypertensive patients (Zafar, Gowani, Irani, \& Ishaq, 2008). However, this is incompatible with the international studies conducted in China (Zhang et al., 2009) and USA (Ong \& Cheung, 2007) which have reported improved awareness and knowledge. These differences in results could be attributed to significant difference in literacy rates as more than half of the participants of our study had no education.

It was reassuring to see that majority of the patients were knowledgeable about the seriousness of the condition to their health due to uncontrolled BP. Ninety percent of the patients knew that lowering BP would improve a person's health and that they could lower their uncontrolled BP by adjusting their lifestyle. The results are in line with the international study conducted by Susan et al. (Oliveria, Chen, McCarthy, Davis, \& Hill, 2005). This shows their willingness to improve their blood pressure, but due to inadequate knowledge they are unable to do so.

During recent years, SBP has been recognized as the greatest causative agent for the morbidity and mortality associated with CVD and stroke (Oliveria, Chen, McCarthy, Davis, \& Hill, 2005). In several clinical trials it has been demonstrated that a greater reduction in cardiovascular events occur with the treatment of elevated SBP level (Staessen et al., 1997). The results of our study suggest that majority of our patients were unaware of the importance of SBP with respect to management of their heart disease. When they were questioned about which measure is more important, $51 \%$ reported DBP and only $8 \%$ answered SBP. Sixty-five percent of the patients did not know the normal values of SBP or wrongly reported it as $140 \mathrm{~mm} \mathrm{Hg}$ or greater. However, $77 \%$ of the participants correctly quoted normal DBP as $90 \mathrm{~mm} \mathrm{Hg}$ or less, which suggests that they are aware of the cut point for DBP. Only very few people knew that top number is responsible for CVD. These findings are similar to those of a study conducted on patients of Henry Ford Health System in Michigan (Oliveria, Chen, McCarthy, Davis, \& Hill, 2005). The results indicate that physicians must emphasize their patients on importance of elevated SBP and cardiovascular risk.

A large number of participants considered salt intake as the risk factor to be associated with high BP, which is evident from a study done on British population (Ashfaq, Anjum, Siddiqui, Shaikh, \& Vohra, 2007) and in line with findings of another Pakistani study (Beard, Blizzard, O'Brien, \& Dwyer, 1997). Poor awareness was associated with smoking, diabetes mellitus and alcohol intake which is further consistent with the study conducted on hypertensive patients of Pakistan (Zafar, Gowani, Irani, \& Ishaq, 2008). The local data has reported an increase in alcohol consumption in Pakistan and regularity of smoking among adults (Ali, Sathiakumar, \& Delzell, 2006) and children (Rozi, Akhtar, Ali, \& Khan, 2005). As a result, people must be emphasized with the risk factors linked with diabetes mellitus, smoking and excess alcohol intake. A significant number of patients were aware with the fact that stroke and CVD are complications of uncontrolled BP which is similar to findings of Line Aubert (Aubert et al., 1998), Susan (Oliveria, Chen, Mccarthy, Davis, \& Hill, 2005), and a Pakistani study (Ashfaq, Anjum, Siddiqui, Shaikh, \& Vohra, 2007). The results could be overestimated as the study was conducted in cardiology OPD. Conversely, most of the patients were not aware about complications related to eye, kidney, metabolic syndrome and trouble with memory which is consistent with results of other researchers (Kearney et al., 2005). Prompt education of hypertensive patients on complications is essential to increase their drug compliance. An international survey has revealed better drug compliance and follow-up visit among patients who were aware with the morbidities and reduction in life expectancy associated with high BP (Balazovjech \& Hnilica, 1993).

Furthermore, patient's regularity on visiting doctor for HTN and cardiologist for their cardiovascular exam, including ECG and cholesterol level, and having home sphygmomanometer was found to be very low. The results could be attributed to less affordability as most of the patients belonged to low socio-economic status. The attitude of patients to bring about lifestyle changes like rhythmic exercise, weight reduction and less stress was significantly less. This might be because of the perception that lifestyle changes have no impact on high BP management as shown by Aubert (Kearney, Whelton, Reynolds, Whelton, \& He, 2004). According to the study, DASH diet and reduced salt intake improves BP control (Zafar, Gowani, Irani, \& Ishaq, 2008) but participants of 
our study have shown extremely less compliance to these approaches. These results further evaluate insufficient self-care practices of HTN among cardiac patients.

To the best of our knowledge, our research has comprehensively evaluated HTN knowledge especially related to SBP among cardiac patients along with their self-care practices involved in the management of high BP. However, there were a few limitations to our study. Most of the participants belonged to low socioeconomic status and had no education. So the results cannot be generalized to the entire population. Secondly, our sample does not include those who were unstable to attend cardiology OPD. Their views may vary over knowledge and self-care practices of HTN. Apart from this we did not obtain the BP values from medical records for the participants who could not recall their last BP reading.

\section{Conclusion}

According to our results, there is an inadequate general knowledge of hypertension in cardiac patients. Patients do not recognize the significance of elevated SBP levels. The study helped us identify the areas that need to be considered by the awareness programs. People should be encouraged to have their blood pressures checked regularly, especially when they have a family history of hypertension. There is a need to initiate programs that create community awareness regarding long-term complications of uncontrolled hypertension in cardiac patients, particularly elevated SBP levels. Improvement in self-care practices can decrease the mortality rate associated with hypertension.

\section{Funding}

There was no funding for this research.

\section{Conflicts of Interest}

The authors have no conflicts of interests to declare.

\section{References}

Ashfaq, T., Anjum, Q., Siddiqui, H., Shaikh, S. \& Vohra, E. A. (2007). Awareness of hypertension among patients attending primary health care centre and outpatient department of tertiary care hospital of Karachi. The Journal of the Pakistan Medical Association, 57(8), 396-9. PubMed PMID: 17902522

Ali, S., Sathiakumar, N., \& Delzell, E. (2006). Prevalence and socio-demographic factors associated with tobacco smoking among adult males in rural Sindh, Pakistan. Southeast Asian J Trop Med Public Health, 37, 1054-60.

Aubert, L. et al. (1998). Knowledge, Attitudes, and Practices on Hypertension in a Country in Epidemiological Transition. Hypertension, 31, 1136-45. http://dx.doi.org/10.1161/01.HYP.31.5.1136

Balazovjech, I., \& Hnilica, P. (1993). Compliance with antihypertensive treatment in consultation rooms for hypertensive patients. J Hum Hypertens, 7, 581-583.

Beard, T. C., Blizzard, L., O'Brien, D. J., \& Dwyer, T. (1997). Association between blood pressure and dietary factors in the dietary and nutritional survey of British adults. Arch Intern Med, 157, 234-238. http://dx.doi.org/10.1001/archinte.1997.00440230114015

Hoel, D., \& Howard, R. B. (1997). Hypertension-stalking the silent killer. Postgrad MedJ, 101, 116-121.

Izzo, J. L., Levy, D., \& Black, H. R. (2000). Importance of systolic blood pressure in older Americans. Hypertension, 35, 1021-1024. http://dx.doi.org/10.1161/01.HYP.35.5.1021

Kearney, P. M., Whelton, M., Reynolds, K., Whelton, P. K., \& He, J. (2004). Worldwide prevalence of hypertension: A systematic review. J Hypertens, 22, 11-9. http://dx.doi.org/10.1097/00004872-200401 000-00003

Kearney, P. M. et al. (2005). Global burden of hypertension: Analysis of worldwide data. Lancet, 365, 217-23. http://dx.doi.org/10.1016/S0140-6736(05)70151-3

Lawes, C. M., Vander Hoom, S., \& Rodgers, A. (2008). Global burden of blood pressure related disease. Lancet, 371, 1513-1518. http://dx.doi.org/10.1016/S0140-6736(08)60655-8

Levine, C. B. et al. (2003). Effect of amlodipine on systolic blood pressure, 25(1), 35-57.

Lloyd-Jones, D. M., Evans, J. C., Larson, M. G., O'Donnell, C. J., \& Levy, D. (1999). Differential impact of systolic and diastolic blood pressure level on JNC-VI staging. Joint National Committee on Prevention, Detection, Evaluation, and Treatment of High Blood Pressure. Hypertension, 34(3), 381-5. PubMed PMID: 10489380. http://dx.doi.org/10.1161/01.HYP.34.3.381 
National Health Survey of Pakistan 1990-1994. Karachi, Pakistan: Pakistan Medical Research Council. 1998, 50.

Nishtar, S., Faruqui, A. M., Mattu, M. A., Mohamud, K. B., \& Ahmed, A. (2004). The National Action Plan for the prevention and control of noncommunicable diseases and health promotion in Pakistan- Cardiovascular Diseases. J Pak Med Assoc, 54, 14-25

Padwal, R., Strauss, S. F., \& McAlister, F. A. (2001). Cardiovascular risk factors and their effects on the decision to treat hypertension. Evidence-based review. BMJ, 322, 977-980. http://dx.doi.org/10.1136/bmj.322. 7292.977

Oliveria, S. A., Chen, R. S., McCarthy, B. D., Davis, C. C., \& Hill, M. N. (2005). Hypertension knowledge, awareness, and attitudes in a hypertensive population. Journal of general internal medicine, 20(3), 219-25. PubMed PMID: 15836524. Pubmed Central PMCID: 1490067. http://dx.doi.org/10.1111/j.1525-1497. 2005.30353.x

Ong, K. L., \& Cheung, B. (2007). Prevalence, awareness, treatment, and control of hypertension among United States adults 1999-2004. Hypertension, 49, 69-75. http://dx.doi.org/10.1161/01.HYP.0000252676.46043.18

Rahimi, B., \& Rahimi, M. (2006). Evaluation of Relationship Between Boctor-Patient Communication and Adherence of Hypertensive Patient. Research [MD Thesis] Isfahan: Isfahan University of Medical Sciences, pp. 2-3.

Rozi, S., Akhtar, S., Ali, S., \& Khan, J. (2005). Prevalence and factors associated with current smoking among high school adolescents in Karachi, Pakistan. Southeast Asian J Trop Med Public Health, 36, 498-504.

Sarafidis, P. A. et al. (2008). Hypertension awareness, treatment, and control in chronic kidney disease. Am $J$ Med, 121(4), 332-340. http://dx.doi.org/10.1016/j.amjmed.2007.11.025

Staessen, J. A., Wang, J. G., \& Thijs, L. (2001). Cardiovascular protection and blood pressure reduction: A meta-analysis. Lancet, 358, 1305-15. http://dx.doi.org/10.1016/S0140-6736(01)06411-X

Verdecchia, P., Angeli, F., Gentile, G., Mazzotta, G., \&Reboldi, G. (2011). Telmisartan for the reduction of cardiovascular morbidity and mortality. Expert Rev ClinPharmacol, 4, 51-61 http://dx.doi.org/10.1586/ ecp. 10.141

Zafar, S. N., Gowani, S. A., Irani, F. A., \& Ishaq, M. (2008). Awareness of the risk factors, presenting features and complications of hypertension amongst hypertensives and normotensives. JPMA The Journal of the Pakistan Medical Association, 58(12), 711-5. PMID: 19157334

Zhang, X. et al. (2009). Knowledge, awareness, behavior (KAB) and control of hypertension among urban elderly in western China. International journal of cardiology, 137(1), 9-15. PMID: 18691776. http://dx.doi.org/10.1016/j.ijcard.2008.06.003

\section{Copyrights}

Copyright for this article is retained by the author(s), with first publication rights granted to the journal.

This is an open-access article distributed under the terms and conditions of the Creative Commons Attribution license (http://creativecommons.org/licenses/by/3.0/). 